\title{
Improvement of Business Processes Performances through Establishment of the Analogy: Quality Management System - Human Organism
}

\author{
Aleksandar Vujovic 1,* - Zdravko Krivokapic ${ }^{1}$ - Mirko Sokovic ${ }^{2}$ \\ ${ }^{1}$ Faculty of Mechanical Engineering Podgorica, University of Montenegro, Montenegro \\ 2 Faculty of Mechanical Engineering, University of Ljubljana, Slovenia
}

This paper establish a model for improvement of business processes performances based on quality management system (QMS) through a comparison with top organizational performances characterized by criteria i.e. particularities of the business excellence (BE) model. Analogy between QMS and human organism has been established to that effect. This analogy develops into two directions, one of which is used and presented in this paper (related to the analogy with willing functions of the human organism). Based on identification, measurement and analyses of occurrences of nonconformities in relation to requests of ISO 9001 standard, and based on the analogy with the human organism, conclusions about the readiness of organizations of productive and service type in terms of achieving $B E$ have been drawn and areas and priorities regarding the improvement with the aim of achieving top performances have been identified. (C) 2011 Journal of Mechanical Engineering. All rights reserved.

Keywords: improvement processes performances, analogy, decision support system, degree of readiness

\section{INTRODUCTION}

The main objective of this paper is to find an analogy through a comparison between an organization and human body function and to develop an appropriate model for performance improvement of the organization [1]. Applying this model points out crucial points in organization (product/service) which should be improved by priority and tend to gain BE.

There are numerous studies that deal with the research of benefits and disadvantages in systems with implemented QMS. Premises on the insignificance of the system of quality regarding the improvement of performance are based on allegations that by that system, procedures are over-emphasized through an excessive care of implementation or non-coverage by procedures and real quality is neglected [2] to [4]. However, most research works point to real benefits of the ISO 9001 implementation, contrary to those who claim that the price of implementation and maintenance of QMS is bigger than profits realized by it [5] to [8]. There are negative premises in literature related with total quality management (TQM) model regarding influence on organizational performances, as it is also the case with the ISO 9001 model. Such premises point to its inapplicability, and therefore, in this paper and in the idea of association of the ISO 9001 and the $\mathrm{BE}$ model in direction of the improvement, comparison with performances of organizations that have won an award for excellence as a measure of level of the TQM implementation, was pointless. Therefore, the authors [9] and [10] have chosen to point here to pessimistic attitudes and to promote optimistic premises through review and analysis of literary sources related to that subject. Premises that TQM has no efficiency regarding organizational performances have been included. These premises are accompanied by research works that indicate the difficulty or near impossibility of establishing a relation between TQM and organizational values and the belief that such a relation is unreal [11] and [12].

There are many studies that indicate how TQM model implemented into organizational management is not just effective but also efficient even in terms of financial results of the organization [13] to [17]. 
On such a defined basis and assertions that present the majority in literary sources, and point to the positive influence of the ISO 9001 and TQM on organizational performances even in the part of finance, an opportunity emerges that improvement in these models would directly contribute to the improvement of organizational performances. Every nonconformity i.e. disagreement with requests of the ISO 9001 model brings results in weakening of quality management system performances and thereby organizational performances. Hereby conditions are created to identify nonconformities with a term of error and apply the theory of learning based on errors or CBR (Case Based Reasoning) in this paper. Through the application of this theory or learning based on experiences, a system to predict the possibility of error occurrence in the identified areas of the ISO 9001 and to present measures for preventive action in that direction as to indicate possibilities and places for improvement for organizations, is being developed.

Through the established analogy with the human organism and division of its activity to willing and unwilling, an opportunity is created to act upon the analogy with e.g. sportsman, and to make a comparison between middleclass sportsmen (QMS) and top-class sportsmen (system with the award for BE) according to these activities (the ISO 9001 requests). Therefore, it is possible to point to areas that are critical in view of performances and indicate priorities regarding improvements with the aim of achieving top performances.

\section{ESTABLISHMENT OF THE ANALOGY BETWEEN THE QMS AND THE HUMAN ORGANISM}

This paper attempts at dealing with the perfection of functioning of the human body compared with a process modelling structures of the implemented QMS. The challenge was to create a system that is universal for all sizes of organization, which incorporate a large number of gathered data, or a large number of experiences, in order to get a better image of the system status. This should be added to the primary goal which is to develop a model for an improvement of the management system, aimed at achieving $\mathrm{BE}$ according to show off how to maintain and improve the performance of the human body. However, the goal is also to develop a system for measuring the performance and capacity of each activity in the QMS, in order to obtain a true picture of the systems and capabilities in order to define the areas where improvements should be made with a clearly defined intensity of improvement. On this basis, the established analogy is made to compare the elements of implemented QMS to the systems that have been applied for the Quality Award for $\mathrm{BE}$ as a system with high performance. A comparison is made from two aspects; the aspect of errors and in terms of significance of achieving BE. Therefore, indicators about the performance of the system and possible action for improving the system are achieved.

The reason for the application of this approach may be to determinate and establish the links between QMS and artificial intelligence (AI) applications. In this way a basis for developing systems that simulate the human way of its functioning and reasoning is created. These activities are carried out especially in the field of expert systems. Expert systems are highly rated as the most commercialized branch of AI [18] and [19]. These systems are particularly suitable for organizations that tend to $\mathrm{BE}$ and the implementation of TQM strategy [20] and [21].

The authors [20] also have conducted a detailed analysis of the 143 software in the field of quality. The results indicate that the software in the field of quality is usually aimed at the control of documentation, statistical control and analysis, Six Sigma model, corrective action, flowchart and mapping process. Consequently, these represent a kind of automation tool for: the implementation process of document management system, describing the information flows, implementation methods and techniques of quality and more. Thus, it can be concluded that there is no software that is based on the application of AI-tools in terms of defining preventive actions for the improvement of processes.

These views and attitudes were in agreement: that there is no correct programming software that has a strong base of knowledge that could assist in identification of a problem, that not a single expert system that deals with the measurement, evaluation, corrective and 
preventive action to improve organizational performance and the like has been developed [22] to [24]. Such analogies give incentive to create a foundation to set up and enter the field of AI in order to obtain knowledge as one of the most important factors for creating competitiveness in the market [25] to [28]. In need to establish the analogy between the process modulated organizational structure and the human organism, so as to create the system that is independent from organizational functions and based only on the process model, the following division of man functions was made [29] and [30]:

- willing and

- unwilling functions.

Willing functions (term "functions" is used in medical terminology, although it is equally correct, to use a term "activities" in view of the ISO 9000 terminology. For reasons of consistent referencing and the use of theories from the field of medicine, the authors have chosen to use the term functions) are those dependent on man's profession and performed by man's will. They are variable and dictated by a central control of the organism. For example, when a worker at the construction site lifts his hand, this is not the same as when a referee lifts his hand and etc. Willing functions refer to functions of external motoric organs.

The second category is made of unwilling or automatic functions and their use is given by their very existence. Those are functions that are the same in all professions and all the people (considering that they exist, i.e. that an organism is healthy) and do not depend on a man's will but are simply executed. For example, those are the functions of secreting enzymes, hormones, heartbeats, and similarly. They regulate the functions of an organism and those that cannot be controlled [31] and [32]. With such a ratio of functions in the organism, an analogy of the system with implemented quality management system can be established. In order to meet requirements of this paper, only an analogy in terms of willing functions has been considered. An analogy that regards willing functions goes in the direction of classifying organizations into productive and service organizations (Fig. 1), as to:

- Identification of weak spots, namely organizational performances through acquisition of nonconformities and isolation of critical areas by the Pareto method;

- Comparison with top organizational performances in accordance with the assessment applied in the competition for the Oscar for quality award (Serbian national quality award);

- Analysis and conclusion on capacities of production or service organizations for achieving BE.
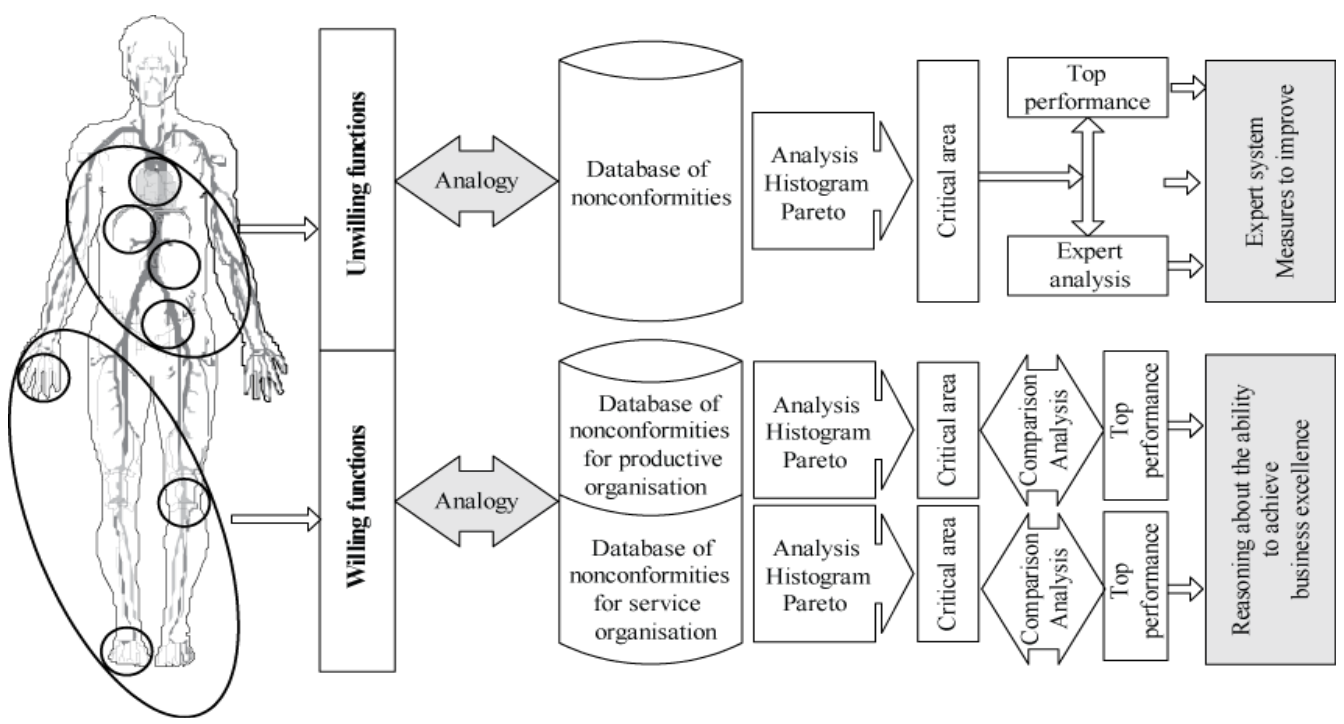

Fig. 1. Analogy with the human organism in order to improve organizational performance 
The analogy established like this justifies the approach to work, which is, just as it is with the man, to monitor process performances in process modulated structure and based on, in medical terms, their condition and diagnostics of non-functionalities, to perform preventive actions in order to maintain the top form.

All functions (willing and unwilling) exist in the organism i.e. they are carried out, under condition that it is a healthy organism, or in better said an organism whose organs perform their given functions. Analogically with that, systems observed from the standpoint of this paper are certified quality management systems, which meet all requirements i.e. perform all functions provided by the ISO 9001 . That is confirmed by the certificate relating to the mentioned referential.

On the other hand, willing functions are carried out by all organisms, but in a different manner depending on activity or profession. Thereby space is created to observe quality management systems and functions they perform based on analogy in different ways, depending on system activities. This justifies a tendency to monitor productive and service organizations in order to reach conclusions about specificities and abilities to achieve BE.

\section{APPLICATIONS OF ANALOGY AND DATA ANALYSIS}

Unique database consisting of $\mathbf{1 0 0 9}$ nonconformities, identified in over $\mathbf{3 5 0}$ organizations was created to meet the demands of this paper, and in that way, a basis was found to carry out an analysis with the aim of defining critical areas, specificities of an organization and guidelines for an improvement in the direction of defining preventive measures and a decrease of corrective action that would correspond to the ISO 9001.

The term nonconformities refer to any nonconformance of requirements of ISO 9001, nonconformity - non-fulfilment of a requirement [33]. During the external audits of QMS, competent and trained auditors can identify several types of nonconformities. The distribution of nonconformities depends on the rules that define the certification body itself. However, for the purpose of this paper classification, which is most common in the literature [34], favoured by authoritative schools in the field of management system and clearly recommended by European guidelines in the subject area, which is split into three levels, is used. The first level is the disagreements that are evaluated as insignificant deviations from the standards and requirements which are interpreted as an oversight or random error. The other two categories are interpreted as nonconformities that represent a great deviation from the essential requirements, which are reflected in the frequent discrepancies in individual requirements, representing a deviation that puts in doubt the stability of the management system and threatens the operations of the organization.

The data base of nonconformities which is under consideration in this paper contains only nonconformities in the domain of the other two categories, and that giving greater importance to this research and gives more significant results. Non-conformances are identified in accordance with the structure requirements defined in the ISO 9001 as follows:

- Quality management systems: 4.1-General requirements, requirements,

4.2-documentation

- Management responsibility: 5.1-management commitment, 5.2-customer focus, 5.3-quality policy, 5.4 -planning, 5.5-responsibility, authority and communication, 5.6-management review,

- Resource management: 6.1-provision of resource, 6.2-human resources, 6.3-infrastructure, 6.4-work environment,

- Product realization: 7.1-Planning of product realization, 7.2-customer-realated processes, 7.3-design and development, 7.4-purchasing, 7.5-production and service provision, 7.6-control of monitoring and measuring devices,

- Measurement, analysis and improvement: 8.1-general, 8.2.1-customer satisfaction, 8.2.2-internal audit, 8.2.3-monitoring and measurement of processes, 8.2.4-monitoring and measurements of product, 8.3-control of nonconforming product, 8.4-analysis of data, 8.5-improvement.

Accordingly, in the field of 8.2.1 from the standpoint of the appearance of non-conformance, organizations are subject to significant and 
frequent or large deviations in the sense that the information about the observations of users is not followed and the methods for obtaining this information are not defined. Moreover, they are not characterized by good communication with customers and similarly.

Similarly, in the field of 8.2.3 with the observed aspect, organizations do not apply appropriate methods for monitoring and performance measurement processes, have no mechanisms for the implementation of corrective measures in cases that have not achieved the planned performance of processes and the like.

If we consider that there are 500 certificates in Serbia and Montenegro in the part of the most competent certification bodies, then the number of 350 makes $70 \%$ out of total number, which indicates the significance of the sample for analysis. Nonconformities represent findings of external revisers who underwent demanding trainings mostly with foreign and competent trainers, which of course increases the significance of data for analysis. These nonconformities were stored in the database classified in relation to requests of standard and activities of the organization by application of realized DSS (Decision Support System) i.e. system for the support of decision-making.

Furthermore, we enter data analysis and integration with results of displayed software solution for DSS. Based on the analogy with willing functions of the human organism, database is being searched separately for productive and service organizations.

During that, the distribution of nonconformities is being observed in the percentage form individually for every request of the standard in accordance with the previously defined division. For the analogy with the human organism, the monitoring of the condition of every activity is realized (or in medical terms, "every function") i.e. transposed in the field of standard, condition of every spot, i.e. the request of the standard, is monitored.

Thereby the inevitable process approach up to the level of activity is being respected, i.e. promoted. In that direction, the percentage display of nonconformities appearance for every request of the standard into a positive form has been converted by subtracting the number of one hundred so as to create a positivistic standpoint and identify the power of activity.

Afterwards, through an introduction of the term Degree of readiness ( $\mathrm{Si}$ ) multiplication of the power of every request given in terms of percentage with weight coefficient is done in relation to the BE (according to EFQM model) obtained as a result of application of AHP (Analytic Hierarchy Process) approach and point to significance of every request of ISO 9001 individually for achieving business excellence [1] and [35] in accordance with the following Eq.:

$$
\begin{gathered}
S_{i(p / u)}=N_{z(p / u)}[\%] \times K_{z(p / u)}, \\
i=1,2, \ldots, 26,
\end{gathered}
$$

where $\mathrm{Si}(\mathrm{p} / \mathrm{u})$ is the degree of readiness for productive/service organizations; $\mathrm{Nz}(\mathrm{p} / \mathrm{u})$ is the power of a standard clause in terms of percentage and $\mathrm{Kz}(\mathrm{p} / \mathrm{u})$ is coefficient of significance for achieving business excellence. The results of the presented approach are shown in Table 1.

Based on the addition of powers for every clause of the standard individually, on the power, i.e. degree of readiness $(\mathrm{S}(\mathrm{p} / \mathrm{u}))$ for the entire organization can be predicted, that is to say, the quality management system in terms of achieving business excellence in accordance with the Eq.:

$$
S_{(p / u)}=\sum_{i=1}^{26} S_{i(p / u)},
$$

where $S_{(p / u)}$ is the degree of readiness for the entire system of productive/service organization.

Applying the defined expression, the following degrees have been obtained:

$S_{(p)}=55.44538$ - Degree of readiness for productive organization;

$S_{(u)}=56.37187$ - Degree of readiness for service organization.

As $S_{(u)}>S_{(p)}$ i.e. service organizations have a larger degree of readiness in terms of achieving business excellence, it can be concluded that: By observing the entire certified QMS, service organizations in our environment, observed from the perspective of occurrence of nonconformities i.e. errors in the system, namely transferred in terms of powers of every request of the standard individually, have a bigger capacity for achieving BE regarding the European Award for Business Excellence. Difference of 0.9265 , regarding the scope of numbers occurring in this research, is significant. If you have a look at the Table 1, this 
difference could signify that service organizations have the "advantage" of e.g. approximately three requests $(7.4,6.3$ i 6.4 or some other combination) because the sum of their degrees of readiness covers up for this difference, and alike. However, if you take a look at the influence of weight coefficients on achieving business excellence, you can find a significant difference both in productive and service organizations in terms of their significance. Thereby, even fulfilment of certain requests of the standard and completion of their improvement in terms of excellence do not have the same meaning. For example, a significant difference between coefficients of significance of clause 8.2.1 and clause 6.4 of the standard has been observed.

Thereby, both fulfilment of these clauses and completion of their improvement do not have the same meaning. Research was continued in that direction, and by applying Pareto method, the most significant requests of the standard were identified i.e. requests that participate with over $70 \%$ in the total sum of their weight coefficients, for productive and service organizations independently.

Through application of the Pareto method, following requests were identified as the most significant requests in achieving business excellence:

- for productive and service organizations, requests - 8.2.3, 8.2.1, 8.5, 8.4, 5.5, 8.2.4, 5.6, $5.3,7.1$ and 4.1 ,

We can examine readiness of productive and service organizations in terms of achieving critical requests for BE. That conclusion points to the speed of achieving business excellence considering that there are great preconditions for organizations with bigger capacity to meet critical requests and improvements in that part, to achieve business excellence faster too.

In that direction, a term of critical degree of readiness in accordance with the Eq. has been introduced:

$$
S_{k(p / u)}=\sum_{i=1}^{10} S_{i(p / u)},
$$

where $S_{k(p / u)}$ is critical degree of readiness for the entire system of productive/service organization.
Based on the expression for critical degree of readiness, the following is obtained:

$S_{k(p)}=34.13428$ - Critical degree of readiness for productive organizations,

$S_{k(u)}=31.47164$ - Critical degree of readiness for service organizations.

Table 1. Review of the degree of readiness for productive and service organizations in relation to every request of the standard

\begin{tabular}{|c|c|c|c|c|c|c|}
\hline 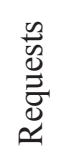 & 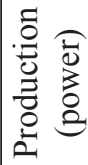 & $\underbrace{\frac{B}{N}}$ & $\stackrel{\overrightarrow{3}}{i}$ & 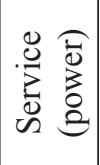 & $4^{3}$ & $\underbrace{ミ}$ \\
\hline 823 & 50 & 0.083 & 4.15 & 50 & 0.083 & 4.15 \\
\hline 821 & 66.67 & 0.082 & 5.46694 & 33.33 & 0.083 & 2.76639 \\
\hline 85 & 37.14 & 0.069 & 2.56266 & 68.57 & 0.069 & 4.73133 \\
\hline 84 & 57.9 & 0.067 & 3.8793 & 42.1 & 0.067 & 2.8207 \\
\hline 55 & 66.67 & 0.066 & 4.40022 & 36.67 & 0.066 & 2.42022 \\
\hline 824 & 40 & 0.064 & 2.56 & 70 & 0.064 & 4.48 \\
\hline 56 & 44 & 0.059 & 2.596 & 58.67 & 0.056 & 3.28552 \\
\hline 53 & 70 & 0.054 & 3.78 & 50 & 0.054 & 2.7 \\
\hline 71 & 56.52 & 0.04 & 2.2608 & 47.83 & 0.04 & 1.9132 \\
\hline 41 & 65.22 & 0.038 & 2.47836 & 56.52 & 0.039 & 2.20428 \\
\hline 51 & 72.73 & 0.038 & 2.76374 & 72.73 & 0.037 & 2.69101 \\
\hline 75 & 37.5 & 0.038 & 1.425 & 67.19 & 0.037 & 2.48603 \\
\hline 54 & 48.72 & 0.037 & 1.80264 & 53.85 & 0.037 & 1.99245 \\
\hline 83 & 50 & 0.036 & 1.8 & 65.39 & 0.036 & 2.35404 \\
\hline 52 & 40 & 0.035 & 1.4 & 100 & 0.035 & 3.5 \\
\hline 81 & 60 & 0.033 & 1.98 & 100 & 0.034 & 3.4 \\
\hline 822 & 46.3 & 0.032 & 1.4816 & 57.41 & 0.032 & 1.83712 \\
\hline 73 & 76.19 & 0.026 & 1.98094 & 47.62 & 0.026 & 1.23812 \\
\hline 61 & 100 & 0.022 & 2.2 & 50 & 0.021 & 1.05 \\
\hline 72 & 56.76 & 0.022 & 1.24872 & 48.65 & 0.022 & 1.0703 \\
\hline 42 & 49.26 & 0.019 & 0.93594 & 51.85 & 0.019 & 0.98515 \\
\hline 76 & 44.68 & 0.018 & 0.80424 & 61.7 & 0.018 & 1.1106 \\
\hline 62 & 62.07 & 0.008 & 0.49656 & 43.1 & 0.008 & 0.3448 \\
\hline 74 & 52.94 & 0.008 & 0.42352 & 49.02 & 0.008 & 0.39216 \\
\hline 63 & 50 & 0.005 & 0.25 & 53.33 & 0.005 & 0.26665 \\
\hline 64 & 63.64 & 0.005 & 0.3182 & 36.36 & 0.005 & 0.1818 \\
\hline
\end{tabular}

As $S_{k(p)}>S_{k(u)}$ it can be concluded that productive organizations in the system of numbers shown in Table 1 have a significant "advantage" in achieving BE in relation to service organizations. Therefore, productive organizations may establish the BE "faster" in the critical part. 
The difference between critical degrees of readiness is 2.66264 , which could e.g. conform to request 8.5 at the productive organizations.

The research was further elaborated in order to indicate critical areas from the standpoint of occurrence of nonconformities in productive and service organizations and the examination of correspondence with significances of the request in the part of achieving BE.

The aim was to indicate whether certain critical areas in the system correspond to significant requests for achieving $\mathrm{BE}$ i.e. requests that have pronounced weight coefficients.

Those are also requests that require special attention from the standpoint of improvement and defining measures in terms of prevention in order to "strengthen" those areas and thereby create preconditions for achieving BE, namely, improve organizational performances in accordance with a tendency of achieving BE.

At the same time, the Pareto method (70/30) was carried out and based on that critical areas can be defined as follows:

- for productive organizations, requests - 4.2, 5.6, 7.5, 8.2.2, 7.6, 7.4, 8.5, 6.2,

- for service organizations, requests - 4.2, 6.2, 5.6, 7.4, 8.2.2, 7.5, 8.2.1, 5.5, 7.2, 5.4.

Now common requests that are critical from the standpoint of occurrence of nonconformities and that have significant weight coefficients in terms of achieving business excellence are searched for. Common requests in those terms that present either critical areas or areas of special significance for the implementation of improvement measures in one are shown in Table 2.

Therefore, priority requests or areas of the standard wherein urgent improvements from the standpoint of achieving top performances based on the $\mathrm{BE}$ model should be done, i.e. areas whereupon "strong" and priority preventive measures should take place, are as follows:

- requests 5.6 and 8.5 for productive organizations and

- requests 5.6, 5.5 and 8.2.1 for service organizations.

Now an analysis of individual requests, observing their "readiness" regarding the percentage of occurrences of nonconformities, and on the other hand their weight coefficients in achieving BE, with a previously stated goal which initiated further analysis up to this level, can be performed.

Clause 5.6 observed from the perspective of occurrence of nonconformities, is especially pronounced both at productive and service organizations, and a significant number of nonconformities have been found within it.

On the other hand, in relation to $\mathrm{BE}$ it has a medium value of weight coefficient in the part of critical coefficients. Coefficients imply that it is necessary to carry out improvement measures of "medium intensity" both at productive and service organizations in order to reduce a great number of nonconformities and satisfy a coefficient of medium significance in the group of critical coefficients.

Service organizations have the "advantage" in this part, considering that the coefficient of significance is approximately the same, while the number of nonconformities is smaller in relation to productive organizations and area 5.6. A considerable number of nonconformities imply the considerable number of experiences of others too, and based on the approach applied in this doctoral thesis or the approach of learning based on experiences of others, it is possible to carry out a significant number of preventive actions for this area, that would provide an improvement of this area of the standard.

Area 8.5 has been identified as critical in the part of productive sector regarding the occurrence of nonconformities and belongs to the "lower" A class of the Pareto classification. Still, as a critical area it is significant for improvement and has a priority in relation to other areas, and especially because its weight coefficient in achieving $\mathrm{BE}$ is pronouncedly big. Therefore, improvement in this part with "strong" preventive measures provides a significant advance of organization i.e. QMS towards BE. The results presented in [36] show a certain congruence and similarity in the conclusion. According to this approach, this is also the last area of the standard that has special and priority significance for improvement.

In service organizations, the area of the clause 8.2.1 emerges as a critical area regarding the occurrence of nonconformities. According to the Pareto's division this area belongs to the "lower" A class. Great significance has been 
identified also regarding the significance of the coefficient that belongs to this clause in terms of achieving BE. In addition, it is "worrying" that a large number of nonconformities at service organizations has occurred exactly within one of the essential requests of the standard, i.e. user satisfaction. This observation becomes more significant if we bear in mind that in our situation it is evident that the economy now for the most part relies, on the service sector.

Table 2. Review of priority areas for improvement

\begin{tabular}{|c|c|c|c|c|c|c|c|}
\hline \multicolumn{4}{|c|}{ Productive organizations } & \multicolumn{4}{|c|}{ Service organizations } \\
\hline 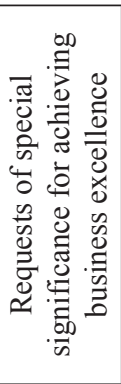 & $\begin{array}{c}8.2 .3 \\
8.2 .1 \\
8.5 \\
8.4 \\
5.5 \\
8.2 .4 \\
5.6 \\
5.3 \\
7.1 \\
4.1 \\
\end{array}$ & 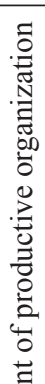 & 5.6 & 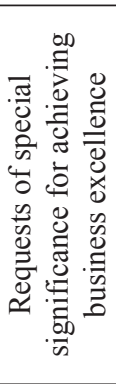 & $\begin{array}{c}8.2 .3 \\
8.2 .1 \\
8.5 \\
8.4 \\
5.5 \\
8.2 .4 \\
5.6 \\
5.3 \\
7.1 \\
4.1\end{array}$ & 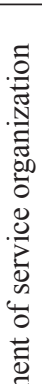 & 5.6 \\
\hline 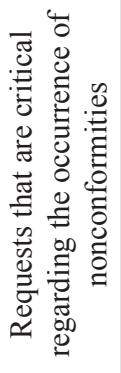 & $\begin{array}{c}4.2 \\
5.6 \\
7.5 \\
8.2 .2 \\
7.6 \\
7.4 \\
8.5 \\
6.2\end{array}$ & 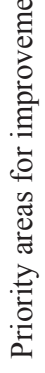 & 8.5 & 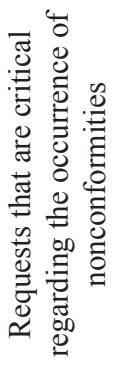 & $\begin{array}{c}4.2 \\
6.2 \\
5.6 \\
7.4 \\
8.2 .2 \\
7.5 \\
8.2 .1 \\
5.5 \\
7.2 \\
5.4\end{array}$ & $\frac{\overrightarrow{0}}{4}$ & $\begin{array}{c}5.2 .1 \\
5.5\end{array}$ \\
\hline
\end{tabular}

The above mentioned is also the reason why a special analysis of nonconformities in this part for service organizations should be carried out, and a strong and priority improvement should be defined.

In this way service organizations can "strengthen" in terms of achieving top performances and thereby create preconditions for strengthening entire economic structure and the most important area in our conditions, i.e. service sector and relation with the user, namely accomplishment of their unreserved pleasure.

As the last one out of three critical areas in the part of the service sector, with a significant weight coefficient in the part of achieving BE, area 5.5 has been identified. It belongs to the "lower" A class of Pareto's classification of nonconformities and brings the medium significant weight coefficient for BE. It does not occur as a critical area in productive organizations, which can be "justified" by clearly defined procedures in technological descriptions of jobs at processes of production and in productive systems in general. This can indicate that service organizations must finally commit to a procedural way of operation and that service must finally be considered as a product in terms of a division into four generic products, as defined by the standard. Therefore, it is also a priority in this part to define and implement clear preventive measures that shall bring service organizations closer to the systems with excellent organizational performances.

It is now interesting to move in the direction of identification of areas for achieving $\mathrm{BE}$ in service organizations in relation to productive organizations in terms of the previously presented difference regarding the satisfaction of requests with critical coefficients and regarding the "advantage" of productive organizations. This approach provides priorities for improvement in service organizations, which is highly significant considering the orientation of our business systems towards the service sector. It has already been mentioned that in the part of priority areas for improvement, in the clause 5.6, service organizations have an advantage over productive organizations. It is the similar with clause 8.5 , which is critical from the standpoint of nonconformities for productive organizations. Service organizations have the advantage in that part. Therefore, it is evident that the mentioned difference emerges in clauses 8.2.1 and 5.5 regarding service organizations and that service organizations lack the "capabilities" in that part. This is a cause for concern, because those are two very important areas that represent one of the essential values of the standard. Therefore, it can be concluded that improvement measures must be urgently defined with priority in terms of preventive action in user satisfaction and in the part of responsibilities, authorizations and communications of the service sector.

If we take a look at the list of "coefficients of significance" for BE achieving (Table 1), especially the most important ones and make a comparison with the list of variables and their significance in terms of: Business Process Reengineering (BPR), manufacturing strategy, 
benchmarking and performance measurement, being the result of the appreciated research conducted in Slovenia [37] and [38] significant intercompatibility may be found.

The concerned compatibility is especially reflected in the following variables, evaluated in the relative research as highly significant for the following four projects, i.e.: customer satisfaction, quality, employee satisfaction and personal growth, customer adaptability, identification of top managers with BPR goals, strong process orientation, results orientation, direct customer cooperation. On the other hand, the above mentioned four areas are considered as highly important for any market-oriented organization, thence it can be concluded that organizations by strengthening their capacities in areas of presented "coefficients of significance" (especially the most important ones), are not only strengthened in terms of the BE achieving as per European Award model, but also in the stated four areas.

\section{FINAL OBSERVATIONS}

Through respect of the stated approaches and models, we can point to the situation of service and productive sector in our conditions of business operation. It proves that, observed at the level of entire certified quality management system (QMS), including all requests of the standard, service organizations have a significant advantage in comparison with productive sector in terms of achieving business excellence (BE). Therefore, expressed in sports terminology, productive organizations in our conditions are in better form and have a better ability for achieving top results. Or in accordance with the process approach, service organizations collectively have better performances of activities in the certified QMS. It is interesting that through further analysis based on stated approaches and models, condition was changed in the part of the most significant activities, which build organizational BE or are characterized as a "top sportsman" in sport. In those terms, productive organizations have a significant advantage over organizations from the service sector. It could be said that productive organizations would faster achieve $\mathrm{BE}$ in that critical part, and thereby they would have conditions to achieve that in the entire QMS, considering that the critical part implies $70 \%$ of the most significant and demanding areas of the ISO 9001 standard regarding the influence on achieving BE.

Conditions like this represent a good foundation for research in terms of identification of critical areas, i.e. areas of priority significance concerning improvement. In that way, requests 5.6 and 8.5 for productive organizations and requests 5.6, 8.2.1 and 5.5 for service organization have been isolated as critical and of the biggest priority for improvement.

The research has resulted in a difference between degrees of readiness, in terms of the advantage of productive organizations in the direction of achieving BE. The analysis led to the conclusion that service organization should inevitably and with priority focus their activities on improvement of their process on areas of user satisfaction (8.2.1) and responsibilities, authorizations and communications (5.5), in order to annul their delay after productive organizations towards the BE. Through urgent and planned improvements in these areas, service organizations can make an important stride towards BE and improvement of their performances to that effect. The strengthening, especially in areas having high "coefficients of significance", leads to a significant progress in terms of: business process reengineering, manufacturing strategy, performance measurement and benchmarking, as very important aspects of market-oriented organization.

In terms of practical implementation, through the solutions presented in this paper, the organizations are suggested to consider the areas of priority from the viewpoint of defining and implementing the measures for improvement in the form of corrective and preventive actions as well. These areas are preferential, but not the only ones. The intensity of improvement measures is defined by "coefficients of significance" presented in this paper and leads to top results based on the model for the European Award for Business Excellence. By using this model in practice, the organizations can efficiently and effectively reach the "top form" based on the priorities and guidelines presented in this paper.

On the basis of "Case Based Reasoning theory", the organization planning to implement 
QMS or upgrading a performance of the system to the highest level, a strategy to prevent the errors in the critical areas and also strengthen the areas of priority for BE achieving should be developed. These experiences and results may be useful to the organizations for defining their strategies based on experiences (cases) of the other organizations. Also, it can be used for encouraging and stimulating the organization to achieve top results and also their involvement in European norms and criteria for BE achieving.

Throughout this methodology and based on the indicators obtained during previous QMS internal and external audits, the organization can measure its "degree of readiness" for BE achieving, and find its position and compare to the other organizations accordingly.

The expert system was implemented and tested in practical, real conditions in the organization that has a clear commitment to participate in the competition for the European Award for Business Excellence, also providing important measures in that direction. The implementation of the system is scored with $92 \%$ satisfactory mark in terms of: impact of the selected solution to the organization of business activities and new expert system benefits. In this sense, within the organization, a reorganization of the priority areas from the viewpoint of improvement has been carried out, preventive measures for the potentially unstable areas have been implemented and the measures for the improvement (offered by this system) leading to achieving BE have been applied.

\section{REFERENCES}

[1] Vujovic, A. (2008). Improvement of business processes performances based on management systems by using artificial intelligence. Ph. Dissertation, Faculty of Mechanical Engineering, Podgorica.

[2] Seddon, J. (2006). In pursuit of quality: Case against ISO 9000. Oak Tree Press, Cork.

[3] Cuff, E., Sharrock, W., Francis, D. (2003). Perspectives in sociology. $4^{\text {th }}$ ed., Routledge, London.

[4] Wenger, E. (2007). Communities of practice: learning, meaning, and identity. Cambridge University Press, Cambridge.
[5] Casadesus, M., Jimenez, G. (2000). The benefits of the implementation of the ISO 9000 standard: empirical research in 288 Spanish companies. The TQM Magazine, vol. 12 , no. 6 , p. 432-41.

[6] Schenkel, A. (2004). Conceptualizing and exploring the organizational effects of ISO 9000: insights from the Oresund bridge project. Total Quality Management, vol. 15, no. 8, p. 1155-1168.

[7] Koc, T. (2007). The impact of ISO 9001 quality management systems on manufacturing. Journal of Materials Processing Technology, vol. 186, no. 1-3, p. 207-213.

[8] Diaye, M.A., Greenan, N., Urdavinia, M. (2006). Subjective evaluation of performance through individual evaluation interview: Empirical evidence from France. Conference on Analysis of Firms and Employees-CAFE, Nüremberg.

[9] Eskildson, L. (1994). Improving the odds of TQM success. Quality Progress, vol. 27, no 4, p. 61-63.

[10] Harary, O. (1999). Ten reasons why TQM doesn't work. Management Review, vol. 86, no. 1, p. 38-44.

[11] Bergquist, T., Ramsing, K. (1999). Measuring performance after meeting award criteria. Quality Progress, vol. 32, no 9, p. 66-72.

[12] Przasnyski, Z., Tai, L. (1999). Stock market to Malcolm Baldrige national quality award announcement. Does quality pay? Total quality Management, vol. 10, no. 3, p. 391398.

[13] Schaffer, R., Thompson, H. (1992). Successful Change Programs Begin with Result. Harvard Business Review, Jan-Feb, p. 80-89.

[14] Eriksson, H., Hansson, J. (2001). The impact of TQM on financial performance. Measuring Business Excellence, vol. 7, no. 1, p. 36-50.

[15] Reed, R., Lemak, D., Mero, N. (2000). Total quality management and sustainable competitive advantage. Journal of Quality Management, vol. 5, no. 1, p. 5-26.

[16] Simmons, B., White, A. (2000). The relationship between ISO 9000 and business 
performance: Does registration really matter? Journal of Management, vol. 11, no. 3, p. 330-343.

[17] Corbett, J., Montes, J., Kirsch, A., AlvarezGil, J. (2002). Does ISO 9000 certification pay. ISO Management System-Special Report, Jul-Aug, p. 31-40.

[18] Bidgoli, H. (1997). Modern information system for managers. Department of Management, California State University, Bakersfield.

[19] Welbank, M. (1983). A review of knowledge acquisition techniques for expert systems. Martlesham Consultancy Services, Ipswich.

[20] Winn, G., Gopalakrishnan, B., Akladios, M., Premkumar, R. (2005). Expert systems - what SH\&E managers need to know about software verification and validation. Professional Safety, vol. 50, no. 8, p. 45-52.

[21] Stein, W., Miscikowski, D. (1999). Failsafe: supporting product quality with knowledgebased systems. Expert Systems with Applications, vol. 16, no. 4, p. 365-377.

[22] Mohan, R., Miller, D. (2004). Expert systems applications for productivity analysis. Industrial Management \& Data Systems, vol. 104, no. 9, p. 776-785.

[23] Srdoc, A., Sluga, A., Bratko, I. (2005). A quality management model based on the deep quality concept. International Journal of Quality \& Reliability Management, vol. 22, no. 3, p. 278-302.

[24] Liao, S. (2005). Expert system methodologies and applications - a decade review from 1995 to 2004. Expert Systems with Applications, vol. 28, no. 1, p. 93-103.

[25] Augier, M., Knudsen, T. (2004). The architecture and design of the knowledge organization. Journal of Knowledge Management, vol. 8, no. 4, p. 6-20.

[26] Kreng, V., Ming Tsai, C. (2003). The construct and application of knowledge diffusion model. Expert Systems with Applications, vol. 25, no. 2, p. 177-186.

[27] Shin, M., Holden, T., Schmidt, A. (2001). From knowledge theory to management practice: towards an integrated approach. Information Processing and Management, vol. 37, no. 2, p. 335-355.
[28] Murray, J., Chao, M. (2005). A cross-team framework of international knowledge acquisition on new product development capabilities and new product market performance. Journal of International Marketing, vol. 13, no. 3, p. 54-78.

[29] Relja, M., Klepac, N. (2002). From gene to therapy - huntington's korea. Biochemia medica, vol. 12, no. 1-2, p. 35-39.

[30] Belak, L., Gacina, N., Radic, T. (2005). Food technology. High school for management in tourism in Sibenik, Sibenik. (in Serbian)

[31] Vilber, K. (2002). No limits-Popular psychology. Babun, Beograd. (in Serbian)

[32] Gilja, I. (2005). Prostate urinary incontinence. Medix, vol. 11, no. 60-61, p. 119-120.

[33] ISO 9000:2005. (2005). Geneva, International organisation for standardization, Geneva.

[34] Vujovic, A., Krivokapic, Z. (2006). Implementation of information technology for the purpose of quality management system improvement. Strojniški vestnik Journal of Mechanical Engineering, vol. 52, no. 7-8, p. 477-483.

[35] Vujovic, A., Jovanovic, J., Krivokapic, Z., Perovic, M. (2007). Assignment significant coefficients of principles QMS in achievement business excellence. ICQME International conference, Miločer-Budva.

[36] Maglic, L., Kondic, Z., Kljajin, M. (2009). Quality audits of management systems. Strojniški vestnik - Journal of Mechanical Engineering, vol. 55, no. 11, p. 695-700.

[37] Vujica-Herzog, N., Polajnar, A., Tonchia, S. (2007). Development and validation of business process reengineering (BPR) variables: a survey research in Slovenian companies. International Journal of Production Research, vol. 45, no. 24, p. 5811-5834.

[38] Vujica-Herzog, N., Tonchia, S., Polajnar, A. (2009). Linkages between manufacturing strategy, benchmarking, performance measurement and business process reengineering. Computers \& Industrial Engineering, vol. 57, no. 3, p. 963-975. 